\title{
Reading Between the Lines: Gender Stereotypes in Children's Sport-Based Books
}

\author{
Jennifer T. Coletti Veronica Allan \\ Queen's University York University \\ Luc J. Martin \\ Queen's University
}

\begin{abstract}
A child's first contact with media and culture typically comes from books they are exposed to in the home and at school. The narratives presented contribute to the early reinforcement of gender roles and norms and can greatly influence the way that young girls perceive and experience sport. The purpose of this study was to explore the narratives within sport-based books geared toward a young female audience to determine the extent to which they promote the engagement of girls in sport. A pragmatic literature search was conducted to obtain books that met our inclusion criteria. Books $(n=28)$ were analyzed based on the age of their intended audience (aged 3-5, 6-8, and 9-12 years) using thematic narrative analysis. Although the authors promoted the engagement of girls in sport, underlying gender stereotypes were nevertheless salient. Across the books, themes involved the emphasis of "feminine" sports as a context for diversity and learning, the need to understand development as a process, the importance of relationships, and implications pertaining to perceptions of capability as female athletes. Most importantly, the application of a critical feminist lens enabled us to identify an underlying theme-the reinforcement of gender stereotypes - that permeated the storylines and served to undermine the potential adaptive messaging intended by authors. These findings suggest the need for greater attention toward the complexity of female sport and a cultural shift in thinking toward gender equity rather than simply increasing sport access for female participants.
\end{abstract}

Keywords: children's literature, critical feminist theory, female athlete, narrative inquiry

Few would argue that sport has historically functioned as a male endeavor. Indeed, society continues to favor men and boys and discourages girls and women through a lack of opportunities, accompanying stereotypes, and inadequate financial support. One reason for this is that female athleticism counters the traditional gender norms that are deeply rooted in society (Hanson, 2012). Of course, considerable advancements pertaining to women in sport have taken place over the past century. For instance, the implementation of Title IX in the United States spurred a movement to celebrate female athletes and recognize women sport leaders in popular culture (Adams \& Leavitt, 2018; Whiteside, Hardin, DeCarvalho, Carillo, \& Smith, 2013). Nevertheless, female representation and recognition in sport have yet to catch up to that of their male counterparts.

Inequities in female representation and participation in sport begin at a young age. For example, across North America, the United Kingdom, and Australia, research demonstrates that girls are less likely to participate in sport and also drop out when they do (Canadian Women and Sport, 2016; Clearinghouse of Sport, 2020; Sport England, 2019; Woman's Sport Foundation, 2020). Consequently, girls and women are less likely to be afforded the physical and mental health benefits of regular physical activity (e.g., Janssen \& LeBlanc, 2010; Poitras et al., 2016), as well as the added psychosocial benefits that sport participation can offer (Eime,

Coletti and Martin are with Queen's University, Kingston, Ontario, Canada. Allan is with York University, Toronto, Ontario, Canada. Coletti (14jtc5@queensu.ca) is corresponding author.
Young, Harvey, Charity, \& Payne, 2013). This latter point is particularly poignant considering that when girls and women $d o$ participate in sport, they have the opportunity to experience positive gender construction, healthy body image, quality relationships with peers and adults, and improved inclusion and diversity of perspectives (Canadian Women and Sport, 2012).

One reason for these inequities could be the way girls are socialized into sport. For example, girls continue to experience "old-fashioned" attitudes that position sport as an activity that is predominantly for boys (Canadian Women and Sport, 2016). Notably, contact sports such as ice hockey, soccer, and boxing continue to be considered masculine, whereas activities like dance and gymnastics are characterized as feminine (Plaza, Boiché, Brunel, $\&$ Ruchaud, 2017). In this regard, traditional beliefs or stereotypes about female physical ability and interests continue to have an impact on girl's and women's sport experiences and participation patterns. Indeed, societal ideologies of gender roles and behavioral norms shape children's perceptions of their own and their peers' gender schemas (i.e., beliefs about gender that influence behavior) early in development. Whereas sex refers to the biological characteristics of one's reproductive system, gender encompasses the roles and behaviors socially constructed by society. Accordingly, gender schemas begin to develop around the age of 3 years old and shape children's sense of their own gender (i.e., gender identity), which may differ from that which is traditionally associated with the sex assigned at birth (Leaper \& Friedman, 2007).

Theories of gender development suggest that a combination of social-structural, interpersonal, cognitive-motivational, and biological influences shape children's gender self-concepts and, 
subsequently, their behaviors. Opportunities to practice these behaviors and experience the resulting constraints also influence the way children learn gender norms (Bussey \& Bandura, 1999; Leaper \& Friedman, 2007). Correspondingly, gender schemas are not set and can change across the age span and with regular exposure to counter-stereotyped behaviors and practices (Leaper \& Friedman, 2007). Nonetheless, children's gender schemas play a role in dictating their interests, and, as a result, children demonstrate a tendency to participate in activities that most closely align with their gender expectations (Leaper \& Friedman, 2007)—such as playing with toys considered to be masculine (e.g., monster trucks, construction vehicle) or feminine (e.g., baby doll, tea set; Weisgram, Fulcher, \& Dinella, 2014).

Although significant others, including family members, teachers, and peers, represent major influencers for gender schemas (Dinella \& Weisgram, 2018), exposure to varied forms of media have also been noted as key sources of cultural information that shape gender norms (Leaper \& Friedman, 2007). Aside from television programs and online platforms (e.g., YouTube), children's first contact with media and culture often comes from books they are exposed to in the home and at school. According to Bussey and Bandura (1999), as children develop, their worldview becomes informed by these cultural ideas of gender. As such, it has been proposed that the themes and narratives presented in children's books contribute to the early reinforcement of gender roles and norms (Heinecken, 2016; Kane, 1998). To demonstrate, in a review of the top-selling 200 picture books from 2001, Hamilton, Anderson, Broaddus, and Young (2006) found that female characters were depicted in a narrow range of professions and most often performed nurturing behaviors. In contrast, male characters demonstrated a diverse range of employment and were engaged in activities that took place outside of the home. Further, the main characters in these books were twice as likely to be males than females. Such examples mirror representations of sports media, where limited coverage is dedicated to women's sport in comparison to men, and when women are presented, arbitrary issues such as femininity and sexuality are often emphasized (Hanson, 2012).

In addition to the cultural ideologies that girls may acquire through books, the ideas represented in sports fiction and the general lack of representation of female athlete role models, may contribute to female learned helplessness (Weiller \& Higgs, 1989), decreased perceptions of self-worth, and sport dropout (Boiché, Plaza, Chalabaev, Guillet-Descas, \& Sarrain, 2014; Heinecken, 2015). This presents a concern considering that young females may be missing opportunities to acquire the potential physical and psychosocial benefits associated with sport participation (Boiché et al., 2014). Previous research exploring girls' sport-based literature has demonstrated affirmations of problematic ideological constructions of sport. For instance, Glenn and King-Watkins (2020) noted that book titles portrayed female-athlete protagonists as atypical compared to nonathlete female characters. This pattern was reinforced through follow-up research whereby the researchers identified a distinction between feminism and athleticism across the books they analyzed (Glenn \& King-Watkins, 2019). In doing so, they noted that the authors of these books failed to acknowledge that duality exists - that is, feminism and athleticism can exist together, and not in opposition to one another. Pertaining to maledominant sports specifically, Glenn and King-Watkins (2019) also highlighted the salient storyline involving girl protagonists having to prove their skill to gain acceptance. Importantly, whereas certain authors have found books to encourage girls' physicality and participation in sport, they also highlight a limited sample to draw conclusions from and note that those adaptive messages are restricted to single chapters that are used to advance other storylines (Roper \& Clifton, 2013; Singleton, 2006).

Two different but complementary traditions of research that hold potential for further examination of female representation in sport-based literature include narrative inquiry and critical feminist theory. Rooted in interpretivism, narrative inquiry accepts that multiple realities exist and that knowledge is socially constructed (Smith \& Sparkes, 2009). Within this paradigm, human beings are viewed as active constructors of meaning, and social realities are considered subjective in nature. Humans are thought to construct meaning through storytelling, which acts to consolidate experiences (Smith \& Sparkes, 2009). The stories that we tell draw on broader narratives that circulate in a society or culture. In other words, narratives are templates from which individual stories are constructed and they enable a rich understandings of people's realities and sociocultural life (Riessman, 1993). Here, storytelling occurs in many different forms such as through conversations or expressed through theater, television, films, advertising, literature, and varied forms of news media. Thus, by exploring stories that are made available for public consumption-such as through storybooks that adults create for children's entertainment and learning - we can identify the dominant narratives that exist in a particular culture and gain insight into the common views or beliefs held within a society more broadly.

In contrast, critical feminist theory provides a lens through which to explore inequalities in social hierarchies that are related to gender, and how they may be revealed through language and messaging (Martin, 2003). Typically, such approaches strive to highlight a need for social transformation pertaining to specific conditions in society (Lazar, 2005). Critical feminist theory is particularly relevant in contemporary society given its emphasis on gender equity, which promotes the expansion and rethinking of narrowly defined roles. Further, critical feminist theory highlights the need to critically appraise current messaging within the available literature, and the important consideration of authorship and ideology involving ingrained adult (i.e., author) assumptions, biases, and norms, hidden within the simplistic and innocent texts, and their potential implication for young readers (Nodelman, 2008). Through such a lens, we can reveal the gendered social practices and lingering stereotypes of women in sport today.

\section{Rationale and Purpose}

Research demonstrates that girls' sport fiction books have a tendency to reaffirm rather than challenge problematic ideologies in sport. In addition, researchers have noted a general scarcity of sport fiction books for girls - a root cause of which could be the stereotypes that portray girls as being uninterested in sport (Heinecken, 2016; Roper \& Clifton, 2013). With this in mind, we explored sport-based children's books to better understand societal beliefs about girls in sport that are being presented to girls at an impressionable age. Grounded in narrative inquiry and critical feminist theory, the purpose of this study was to explore narratives within sport-based children's books geared toward a young female audience (aged 5-12 years) to determine the extent to which they promote the engagement of young girls in sport. The 5- to 12-year-old age range was chosen as it corresponds with the period of time when children begin to develop gender schemas. Additionally, including a wider range allowed us to group the books into different age categories (3-5, 6-8, and 9-12 years) and observe how themes progress as the books begin to target older 
audiences. Lastly, this audience was selected to reflect a population who may soon be entering sport, are in the early stages of their sport experiences, or are making decisions about sampling and specialization in sport (Côté, Baker, \& Abernethy, 2007). Whereas narrative inquiry provided a natural framework through which to understand and analyze stories, critical feminist theory enabled us to explore how the development of gender-related beliefs (i.e., gender schemas) in society, as shaped by narratives about girls and women in sport-based fiction for children, might influence girls' attitudes toward and participation in sport.

\section{Methods}

\section{Book Search and Acquisition}

A literature search was conducted to obtain children's books that met our inclusion criteria. Provided that the emphasis of this project was to evaluate easily accessible books for young females, a pragmatic search involved the following websites: Chapters/ Indigo.ca, Google Books, and Amazon.ca. The search was purposefully conducted in a way that reflected the most realistic and practical way that individuals, such as parents or caregivers, would access books of this genre. Specifically, we were interested in sport-related books with a female protagonist that were geared toward a young female audience (roughly 5-12 years of age). Books also needed to be fictional in nature and to have been published within the last 10 years at the time of the study (20082018). A list of the search terms is provided in Table 1. The decision to narrow the search to fictional books was made to capture the types of books that young people are exposed to most commonly, which-for this age range-includes fiction more often than nonfiction (Renaissance Learning Inc., 2016).

To ensure that our sample of books was indicative of what might be read by the general population, we purposefully sampled 11 individuals $\left(M_{\text {age }}=41.27\right.$ years; $S D=15.85$ years $)$ to recreate our search. These individuals included young professionals (e.g., graduate students, chiropractic interns, and sales representatives), librarians and teachers, and parents. Participants were asked to spend 5-10 minutes online searching for sport-related books geared toward a young female audience with a female protagonist. Instructions for the participants were general so that the process would best capture a typical search within the genre of female youth sport literature and to prevent participants from searching for specific types of narratives. We also asked participants to record their search terms and relevant books identified. In general, participants used similar search terms to those of the research team, including "sports books for girls" and "girls sport" (see Table 1 for a complete list).

The list of books generated through the participants' searches was combined with the results of the initial search and crossreferenced so duplicates could be removed. After reviewing the updated list, two additional criteria were added. First, books were limited to those under 100 pages in length. This criterion was imposed to ensure relevance to the intended population (i.e., 5- to 12-year-old girls), provided that longer books are more likely to target an older audience with more mature content, and as a way to narrow our search to a feasible total for analysis. We acknowledge that girls in the upper end of this age range may be reading books that are longer than 100 pages, yet by consulting the age rating assigned to the books by the authors and publishers, we ensured that we were nevertheless capturing books specifically targeting this age group. Further, when books were found to be from a larger series, only a representative sample was retained to determine whether consistent messaging was presented across the series. Aside from Jake Maddox's Girls Sport Series (which contains $>40$ books), approximately half of the books in all series identified during our search were included in the sample; and only those from the Girls Sport Series that were accessible at local libraries were retained.

As illustrated in Figure 1, a total of 134 books were located. After applying the inclusion and exclusion criteria, this list was reduced to 29 books. The books were obtained from local library branches - and their online resources (i.e., eBooks) — in four Canadian cities. Of the 29 books, 17 were obtained from local libraries and 11 were purchased through Amazon.ca. One book (My Little Tomboy: Little Girls Play Sports Too by Rachel Naughton) could not be obtained and was therefore excluded. As a result, 28 books were retained for the analysis (see Table 2 for a list of these books and publication details).

The books were categorized into three groups based on the age range of the target audience using online book reviews from Chapters.ca and Amazon.ca, as well as published author recommendations. These categories included books targeting 3- to 5-year-olds $(n=12), 6$ - to 8-year-olds $(n=9)$, and 9- to 12-yearolds $(n=7)$. Categories were not completely distinct, and thus, some overlap was present.

\section{Thematic Narrative Analysis}

Grounded in narrative inquiry and critical feminist theory, a thematic narrative analysis was performed (Smith, 2016). Accordingly, patterns in the narrative content and structure of each book were identified within each category and across the sample as a whole. This approach was specifically adopted because, as opposed to a traditional thematic analysis, narrative analysis is grounded in theoretical assumptions that are focused on understanding the central themes of stories, and how they are related within a narrative (Braun, Clarke, \& Weate, 2016; Smith, 2016). Whereas thematic analysis stresses the what of the content, our narrative thematic analysis placed greater emphasis on exploring how female athletes are perceived and represented in society and why this might be (e.g., Riessman, 2008). In this regard, our analysis involved

\section{Table 1 Search Terms Used by Researchers and Participants in Book Search}

\begin{tabular}{ll}
\hline $\begin{array}{l}\text { Search } \\
\text { performed by }\end{array}$ & Search terms used \\
\hline Research team & "girls books"; "girls sports books"; "young girls sports books"; "little girls sports books"; "girls sport"; "kids books"; "3-5"; \\
& "6-8"; "9-12"; "young girls sport books"; "little girls books" \\
Participants & "Girls sport"; "Kids sport"; "Women in sport"; "Female athletes"; "Female runners"; "Young female athletes"; "Famous female \\
$(n=11)$ & $\begin{array}{l}\text { athletes"; "Famous youth athletes"; "Famous girl athletes"; "Girl athlete"; "Sports books kids"; "Sports books girls"; "Girl } \\
\text { sports"; "Sporty girl books"; "Girl power in sports"; "Sport fiction"; "Girl protagonists in sport books"; "Sport novels with girl } \\
\text { protagonists"; "Sport books with girl protagonists"; "Fictional books about girls in sport"; "Youth girls in sports"; "Girls in } \\
\text { sports fiction"; "Books about girls playing sports"; "Books for girls 9-12 sports" }\end{array}$ \\
\hline
\end{tabular}




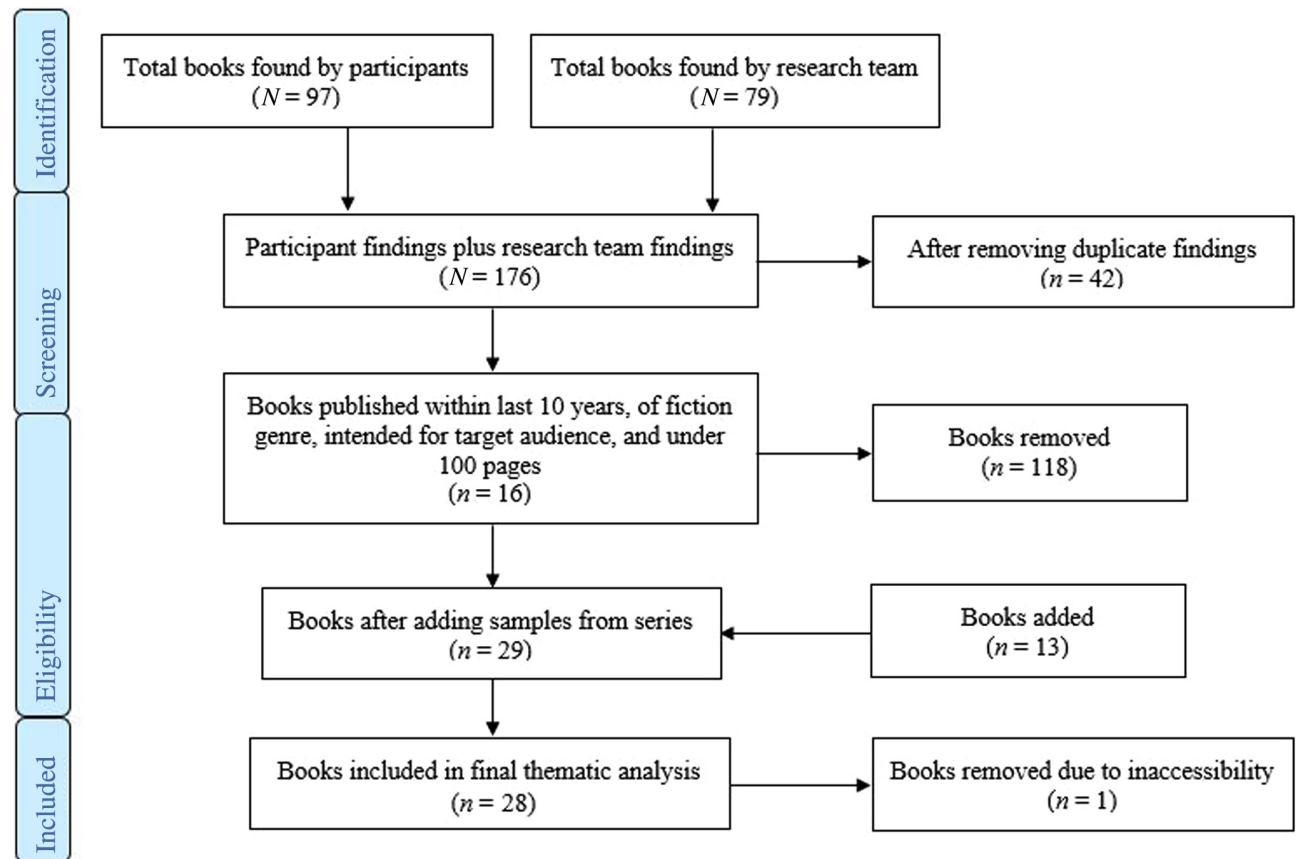

Figure 1 - Flow diagram depicting the book search process.

the identification of themes that acted as windows into deepseated adult knowledge, experiences, and biases held by authors (Nodelman, 2008). We also explored the connection between authors' views and the potential implications for young readers (Nodelman, 2008).

In relation to specific steps for the analysis, we followed guidelines put forth by Smith (2016). To begin, the first author engaged in narrative indwelling by reading each book multiple times. During the first reading, initial thoughts and impressions were noted directly on the books and in a reflexive journal. Additional ideas about what, why, and how messages were being presented were noted during subsequent reviews. This process was undertaken not only for the written words but also for the illustrations within each book (Phoenix \& Rich, 2016). Examples of initial notes and codes from across the texts included "overcoming obstacles," "uniqueness," and "challenging stereotypes" (3- to 5-year-olds); "proving self," "lone girl," and "fun with friends" (6- to 8-year-olds); and "showing off," "sport-related conflict/ rivalry," and "reinforcing stereotypes" (9- to 12-year-olds). Sample codes used for images, which were consistent across all age groups, included "tomboy appearance," "diverse ethnicities," "Barbielike," and "overemphasized femininity." At the end of this process, notes were reviewed to identify recurring ideas and threads that were carried throughout each story. This was repeated for every book in each age category. Once an age category was complete, all themes and notes were reviewed and synthesized so that central themes for that category could be advanced.

In line with our positioning, a critical feminist lens was used during the analysis and construction of themes. We acknowledge that we had preconceived ideas of what to look for, such as resistance from male supporting characters, plots that focused on impressing male peers or included "love triangles," overly feminine illustrations of girl characters, and a lack of emphasis on the competitive nature of girls' sport, as well as a particular rhetoric to be mindful of when reading through each of the books. While some of our preconceived ideas were reinforced (e.g., resistance from male characters), others were also challenged (e.g., plots focused on "love triangles"). As such, throughout the analysis, coauthors acted as critical friends and were asked to review and comment on overviews of the narratives being analyzed by the first author. Their role was to ensure reflection pertaining to themes presented and whether their portrayal was an accurate reflection of the stories analyzed. This was achieved through additional meetings following the analysis of each age grouping of books, frequent dialogue discussing plots, potential codes, and individual perceptions of the content being analyzed.

\section{Results and Discussion}

Generally, the books analyzed for this study promoted the engagement of girls in sport - on the surface. Female characters are presented in male-dominant sports such as ice hockey and baseball; some are seen excelling and achieving high accolades and accomplishments. Storylines focus on several of the benefits of sport participation including the opportunity to have fun with friends and be part of a team, cultivate self-awareness, and develop resiliency. Indeed, at a superficial level, we could summarize the content as emphasizing "girl power." However, the application of a critical feminist lens revealed an underlying theme-the reinforcement of gender stereotypes - that permeated the storylines and served to undermine the potential adaptive messaging likely intended by the authors.

Interestingly, the ways in which gender stereotypes were reinforced differed across the targeted age categories and were expressed to different degrees in each group. Unique "adaptive" themes-in which gender stereotypes were challenged, countered, or simply disregarded-were also identified for each category. Given the nuanced differences in the themes that were identified across each set of books based on the age group that was targeted, we have divided our results and discussion into three sections corresponding to each category (i.e., books targeting 3- to 5-yearolds, 6- to 8-year-olds, and 9- to 12-year-olds). In each category, 
Table 2 Available Books Found Through a Typical Internet Search and That Met Inclusion Criteria

\begin{tabular}{|c|c|c|c|c|c|}
\hline $\begin{array}{l}\text { Age } \\
\text { grouping }\end{array}$ & Title of book & $\begin{array}{l}\text { Year } \\
\text { published }\end{array}$ & Author(s) & $\begin{array}{l}\text { Age range } \\
\text { (years) }\end{array}$ & $\begin{array}{l}\text { Sport } \\
\text { featured }\end{array}$ \\
\hline \multirow{12}{*}{$\begin{array}{l}\text { Group } 1 \\
(3-5 \text { years })\end{array}$} & Girl Running & 2018 & Annette Bay Pimentel & $5-8$ & Running \\
\hline & Sports Day: A Bloomsbury Young Reader & 2018 & Jane Lawes & $5-7$ & Multisport \\
\hline & $\begin{array}{l}\text { Runner Girl Ella's Story: Family Fun Run (Go! Go! Sport } \\
\text { Girls Series) }\end{array}$ & 2014 & Kara Douglass Thom & $5-7$ & Running \\
\hline & $\begin{array}{l}\text { Cheerleader Girl Roxy's Story: Leading the Way (Go! Go! } \\
\text { Sport Girls Series) }\end{array}$ & 2014 & Kara Douglass Thom & $5-7$ & Cheerleading \\
\hline & $\begin{array}{l}\text { Swimmer Girl Suzi's Story: Winning Strokes (Go!Go! Sport } \\
\text { Girls Series) }\end{array}$ & 2014 & Kara Douglass Thom & $5-7$ & Swimming \\
\hline & Little Ballers Of The World Book: Mira Likes to Shoot & 2015 & Stephanie Rudnick & $5-6$ & Basketball \\
\hline & Little Ballers Of The World Book: Katie Likes to Shoot & 2015 & Stephanie Rudnick & $5-6$ & Basketball \\
\hline & Little Ballers Of The World Book: Tammy Likes to Shoot & 2015 & Stephanie Rudnick & $5-6$ & Basketball \\
\hline & She's Got This & 2018 & Laurie Hernandez & $4-8$ & Gymnastics \\
\hline & Olivia Plays Soccer & 2013 & $\begin{array}{l}\text { Tina Gallo and Jared } \\
\text { Osterhold }\end{array}$ & $4-6$ & Soccer \\
\hline & Oddrey Joins the Team & 2014 & Dave Whamond & $4-6$ & Soccer \\
\hline & Just One Goal & 2008 & Robert Munsch & $3+$ & Hockey \\
\hline \multirow{9}{*}{$\begin{array}{l}\text { Group } 2 \\
(6-8 \text { years })\end{array}$} & Pink Laces \& Pony Tails & 2014 & Rob Haswell & $7-9$ & Hockey \\
\hline & Ally Loves Sports: Ally Loves Tennis & 2015 & C.E. Butler & $7-9$ & Tennis \\
\hline & Ally Loves Sports: Ally Loves Basketball & 2015 & C.E. Butler & $7-9$ & Basketball \\
\hline & $\begin{array}{l}\text { Catching the Moon: The Story of a Young Girl's Baseball } \\
\text { Dream }\end{array}$ & 2010 & Crystal Hubbard & $6-10$ & Baseball \\
\hline & Nadia: The Girl Who Couldn't Sit Still & 2016 & Karlin Gray & $6-9$ & Gymnastics \\
\hline & Lucy Tries Soccer (Series) & 2016 & Lisa Bowes & $6-8$ & Soccer \\
\hline & Lucy Tries Hockey (Series) & 2018 & Lisa Bowes & $6-8$ & Hockey \\
\hline & Lucy Tries Luge (Series) & 2015 & Lisa Bowes & $6-8$ & Luge \\
\hline & Lucy Tries Short track (Series) & 2016 & Lisa Bowes & $6-8$ & Short track \\
\hline \multirow{7}{*}{$\begin{array}{l}\text { Group } 3 \\
(9- \\
12 \text { years })\end{array}$} & Soccer Sabotage & 2009 & Liam O’Donnell & $9-12$ & Soccer \\
\hline & Gymnastics Jitters (Jake Maddox Sports Series) & 2012 & Jake Maddox & $8-11$ & Gymnastics \\
\hline & Victory Vault (Jake Maddox Sports Series) & 2011 & Jake Maddox & $8-11$ & Gymnastics \\
\hline & Running Rivals (Jake Maddox Sports Series) & 2008 & Jake Maddox & $8-11$ & Running \\
\hline & Soccer Surprise (Jake Maddox Sports Series) & 2012 & Jake Maddox & $8-11$ & Soccer \\
\hline & Soccer Show-Off (Jake Maddox Sports Series) & 2014 & Jake Maddox & $8-11$ & Soccer \\
\hline & Dancing Solo (Jake Maddox Sports Series) & 2014 & Jake Maddox & $8-11$ & Dance \\
\hline Excluded & My Little Tomboy: Little Girls Play Sports Too & 2015 & Rachel Naughton & - & - \\
\hline
\end{tabular}

dominant themes related to how gender stereotypes are countered and reinforced are presented. To conclude, we advance implications and potential future directions.

\section{Three- to Five-Year-Olds: "Feminine" Sports as a Context for Diversity and Learning}

Among books targeting 3- to 5-year-olds, two adaptive themes were identified: everyone is unique and everyone has to start somewhere. These narratives aimed to promote young girls' early engagement in sport. The authors sought to reinforce healthy habits, a strong work ethic, and a belief in one's unique abilities. To this end, the majority countered traditional gender stereotypes of female athletes by placing emphasis on the sport and positive teammate relationships as opposed to arbitrary non-sport-related topics (see subsequent sections for examples of this tendency). To convey their messages, the authors used relatable characters who either possessed or developed the qualities of unique and hardworking athletes. In doing so, many of the authors also included characters of different races and skill levels to provide young readers with the opportunity to identify with and see themselves in the characters being presented. However, other aspects of diversity were not addressed. For example, none of the authors addressed aspects of religion or ability. In fact, in one example, every primary and supporting character appeared able-bodied. Consequently, work remains to be done to recognize other aspects of diversity in sport and society. Further, despite the positive messaging demonstrated in these themes, these stories also reinforced gender stereotypes in subtle ways-particularly concerning the types of sports chosen as the backdrop for each story. As such, a third and final theme related to the setting of each book: feminine sports are appropriate sports.

Everyone is unique. Several books followed a storyline that emphasized the unique qualities of the primary and supporting characters. Importantly, although the messaging is specific to sport, 
the underlying message is to be yourself and to appreciate diversity. The authors countered the idea that everyone on a team should be similar and equally skilled. Rather, they emphasized that everyone has different strengths to bring to the team, and that capitalizing on differences can be advantageous. For example, in Oddrey Joins the Team by Dave Whamond, the female protagonist is depicted as having an unusual soccer style compared to the best player on the team. All the players try to mimic the best player's style, which leads to poor results during a match; however, Oddrey helped her teammates realize that "each [player] has their own special job" (p. 19) and when performed well, can help the team win. Through these examples, the author stresses the importance of diversity and embracing each other's strengths to create a well-rounded, winning team.

Another example can be drawn from Leading the Way by Tara Douglass Thom. Part of a Go! Go! Sports Girls series, this book featured Sophie, who joins a cheerleading team. The veteran cheerleaders notice her quiet demeanor, an unusual trait for a cheerleader. Her new teammates describe her as "weird" and unfit for the squad and exclude her from team events (e.g., sleepovers). The main character and leader of the team, Roxy, explains to the squad that "[everyone] is a little weird, that's what makes us interesting" (p. 22). Similar to the previous book, the author illustrates how celebrating differences and exploiting them is "what makes the squad shine" (p. 26). Thus, not only does this age category appear to promote uniqueness among members of sport teams, but it also teaches young girls to embrace and be proud of their differences.

In relation to this theme, there is support from the literature for the importance of self-efficacy and role experiences for the promotion of girls in sport. Self-efficacy represents an individual's belief in their ability to succeed in a given task (Bandura, 1997). Here, the authors promoted self-efficacy by placing emphasis on appreciating individual differences and understanding that no one is automatically or immediately skilled. While increased self-efficacy is associated with performance (Moritz, Feltz, Fahrbach, \& Mack, 2000), it is also recognized as an antecedent to developmental outcomes, such as self-regulation, motivation, and coping (Tsang, Hui, \& Law, 2012), and is improved by mastery experiences and verbal persuasion from others (Bandura, 1997). When authors describe how the protagonists recognize their individual talents and help others see theirs, it is an important step in encouraging young female athletes to do the same.

The narrative that emphasizes the importance of individuality and diversity also aligns with research on roles in sport. As discussed in the introduction, roles are something children learn from an early age. In sport, scholars highlight that recognizing ones' role (i.e., role clarity) is positively correlated with athlete satisfaction, continued sport participation, and developmental outcomes such as identity development (Beauchamp, Bray, Eys, \& Carron, 2002; Eys, Godfrey, \& Kim, 2020). There are a variety of important roles in sport aside from those that are more formal such as team captain (e.g., task roles, auxiliary roles, and social roles). The authors from these books emphasized several informal roles that would typically go undiscussed (e.g., the energy player). In this way, authors were showcasing the different ways in which young athletes can help the team-apart from being the most skilled or the team captain.

Everyone has to start somewhere. Another prominent theme among this group of books was that everyone has to start somewhere. In Winning Strokes by Tara Douglass Thom, Suzi desires to be just like her older sister Hanna, a championship-winning swimmer. Although she doubts her talents and abilities, her mother reminds her of the progress she has made since learning to swim. From this discussion and the following quote from Suzi's mother, "even dolphins need to come up for air" (p. 11), the author reminds the readers that no athlete is perfect and developing skill takes hard work and practice. In She's Got This by Laurie Hernandez, Zoe, an American gymnast and Olympic gold medalist is portrayed from her early experiences. Hernandez uses Zoe to illustrate how her journey was full of setbacks and failures. In doing so, she shows how Zoe continued to work hard on her skills and persevered after every fall, eventually leading to her gold medal.

This second theme aligns with a prominent developmental pathway in youth development literature. The Developmental Model of Sport Participation from Côté et al. (2007) outlined how athletes progress through sport and the potential outcomes associated with different paths that can be taken (i.e., sampling or specialization). A key feature of this model is its demonstration of athlete progress through phases, and the emphasis that athlete specialization (i.e., intense training in one sport) should not occur until adolescence. The idea of a phased pathway toward specialization is echoed in several of the books reviewed. Authors stressed the process and journey to elite performance takes practice over time and should not be prioritized at the expense of enjoyment with peers.

Only one book incorporated ideas of sampling (i.e., trying a variety of sports) - a key feature of the Developmental Model of Sport Participation-into the storyline. In Sports Day, the main character Emmie believes she has no sporting abilities. She is afforded the opportunity to try a variety of sports and activities, and learns not only what she is skilled at, but also that she enjoys the experience. Encouraging young children to sample a variety of sports allows them to explore and develop an understanding of their strengths and abilities, likes, and dislikes (Côté, Lidor, \& Hackfort, 2009). Sampling is a well-researched approach to developing the physical, cognitive, and emotional skills of sport and promoting long-term participation - a strategy that is important for encouraging young girls' participation in sport (Côté et al., 2009). Given its significance in the academic literature, this is a topic that could be explored more in children's sports fiction.

Feminine sports are appropriate sports. Despite the positive messaging demonstrated within these themes, these stories also reinforced gender stereotypes in subtle ways-particularly concerning the types of sports chosen as the backdrop for each story. Plots were mainly centered around individual sports or artistic sports like gymnastics, swimming, and cheerleading. Sports such as these are often considered gendered (i.e., primarily engaged in by females). This finding is particularly important for this age group because children are still in the early stages of learning about gender through socialization processes like reading (Weiller \& Higgs, 1989). It is imperative to include female characters who take part in a variety of sports to ensure girls are not only participating in them but are also comfortable and confident when playing nontraditional sports (Weiller \& Higgs, 1989). Weiller and Higgs (1989) proposed that a failure to do so could contribute to female learned helplessness - the feeling a person experiences when she believes others have low expectations of her-especially in sports heavily populated by males.

Limiting the visibility of girls in diverse sports and the development of female learned helplessness may have implications on the sports that girls choose to participate in and their feelings of competence when they begin (Weiller \& Higgs, 1989). Sport research stresses the importance of sampling (i.e., participating in a 
variety of sports and activities; Côté et al., 2007), and the statistics from Canadian Women and Sport (2016) suggest the engagement in a range of sports to be more typical in boys. Taken together, this could suggest that girls are still receiving messaging that sport is generally for boys, which means that sport fiction should reinforce the idea of sampling as a norm or expectation for all.

\section{Six- to Eight-Year-Olds: Emphasizing the Process and the Company}

Among books targeting 6- to 8-year-olds, two adaptive themes were identified: development of sport-specific skills and being part of a team. Similar to the previous age group, these narratives promoted young girls' engagement and continued participation in sport. The authors did so by stressing the time and effort required to develop skill, and also the opportunities to develop friendships with teammates. For this reason, several of the books countered traditional gender stereotypes by showcasing athletes who had succeeded at high levels of competitive sport and by demonstrating positive female relationships between teammates and competitors. However, it is important to highlight that several authors also conveyed messages that reinforced gender stereotypes: proving she belongs and the lone girl.

Development of sport-specific skills. Extending from the previous themes for younger readers, this age group included skill development as a major component to their storylines. Patience and hard work were at the forefront, often having female protagonists begin a new sport and struggle to understand why they were not making progress or could not compete at the same level as more experienced peers. To illustrate the importance of hard work, patience, and goal setting, author Karlin Grey used the story of Nadia Comăneci, a Romanian gymnast and five-time Olympic gold medalist. Grey shows the progression of Nadia's skill development until the perfection of her routine. During the competition, however, Nadia fell multiple times and finished in 13th place. Instead of being upset and frustrated, Grey portrays Nadia's determination through continued practice to the point where she eventually wins first place.

A systematic review looking at reasons why youth dropped out from organized sports found that the two most prominent reasons were lack of enjoyment and perceptions of their physical and sport competence (Crane \& Temple, 2015). Evidence suggests that the most elite athletes often attribute their success to the adversities they experienced during the journey to their goal and the dedication to practice and skill development that was required to reach their elite status (Howells \& Fletcher, 2015). Even within the realm of elite youth sports, White and Bennie (2015) saw that moderate exposure to stressful or challenging events led to positive outcomes such as the development of resilience in gymnasts. Thus, the authors focusing on the process rather than the outcome is important for showing young athletes that adversity is to be expected and should not equate to failure. Such plots are likely to help youth understand the time and effort that are required and to prevent feelings of low self-competence and potential dropout.

Equally important is that in doing so, the authors must be mindful not to give a false impression of meritocracy within sport. Indeed, the storylines here emphasized the importance of developing skills to obtain greater status in sport. Whereas hard work and persistence can certainly improve skills, the authors may have overlooked the broader benefits of sport involvement. In this regard, perhaps less emphasis should be placed on telling girls they need to improve their skill to acquire status and acceptance, and to simply promote sport for the many psychosocial and physical health benefits that come with it. In a similar way, by downplaying the objective of sport emphasizing elite status, authors also should deemphasize that skill is restricted to the individual, because in reality, socioeconomic status, access, and circumstances outside of an individual's control play a large role in determining how far one can advance in sport.

Being part of a team. Another salient theme used by authors pertained to the enjoyment and belonging experienced when working as a team. This is captured in the illustrations of Lisa Bowes' Lucy Tries Soccer. On page four, Lucy is depicted standing side by side with members of her team, arms across each other's shoulders before participating in the practice session. This simple act, often done by professional teams during the playing of the national anthem, is symbolic of unity and the coming together of individuals toward a collective goal. On page 13, Lucy and her teammates are also depicted with smiling faces throughout the story, partaking in team huddles, and frequently referring to the fun they are having with friends. To this end, while it is clear that the supporting characters are Lucy's teammates, Bowes makes a point of using "teammates" and "friends" interchangeably.

In keeping with a focus on friendship and peer relations, authors included narratives that demonstrated primary characters supporting their competitors. Some even showed how you can be friends with competitors and those who surpass you in competition. In Ally Loves Basketball by C.E. Butler, a new player-thought to be one the best in the league-joins Ally's basketball team. While intimidated at first as this posed a threat to Ally's goal of winning the three-point contest trophy, the story follows the development of their friendship and journey from competitor to teammate. This is also illustrated in another of Lisa Bowes' books, Lucy Tries Short Track. Lucy competes against her friends in short track speed skating and although they are competing against one another, when the winner (who is not Lucy) is declared, Lucy congratulates her opponent: "Way to go! .... Great race, Jill! ... . I'm so happy for you!” (pp. 27-28).

Research suggests that youth are motivated to participate in sport for social reasons (Allen, 2003; Smith, 2003). This is not surprising given that humans have a desire to develop meaningful connections with others across the lifespan (Baumeister \& Leary, 1995). As such, sport becomes a setting for youth to establish relationships and fulfill their innate desire to belong (Allen, 2003). Developing positive connections is also known as a prerequisite for positive youth development through sport (e.g., Strachan, Côté, \& Deakin, 2009). A review of social support literature identified five variables positively associated with peer relationships from sport, including athlete motivation, elite sport participation, and friendship quality (Sheridan, Coffee, \& Lavallee, 2014). Moreover, quality relationships with peers are associated with positive selfperceptions, emotions, self-determined motivation, and moral development (Smith \& McDonough, 2008). The social interaction that comes with being involved in a sport is a key factor driving continued sports participation (Smith, 2003). Thus, the authors bringing to light the opportunities to fulfill social connection through sport, offers encouragement for girls to participate, and provides positive role modeling of prosocial behavior. Such messaging could result in more frequent quality interactions with teammates, which are related to increased enjoyment, commitment, teamwork, social skills, and overall positive youth development (Erickson, Wright, Kochanek, \& Vierimaa, 2020).

Proving that she belongs. This second age grouping of books saw a transition toward more explicit messaging and reinforcement of problematic gender stereotypes. With respect to the sports 
chosen, narratives included a greater diversity of sports compared with the first group. For example, more unique sports like speed skating and luge were introduced in the Lucy Tries Sports series. However, two books that included ice hockey and baseball, sports traditionally occupied by males, were accompanied by a struggle for protagonists to compete alongside males and necessitated them to prove that they "belonged." In Pink Laces and Pony Tails, Rob Haswell described a competition between two ice hockey teams: a girls team and a boys team. The boys called the girls "future NHLer's," whereby the NHL was meant to represent "National Hair-bow League" and "Not Here Ladies." Whereas the girls' team consistently struggled to secure ice time for practice, the boys had no issue and appear relaxed and unthreatened by the challenge of playing against a girls' team. In contrast, Haswell described the amount of practice and work put in by the girls in preparation for the game. Even though the girls did not win the game, the boys were shocked by their skill and ability, eventually accepting them as fellow ice hockey players.

Whereas it is encouraging that more sports were being made visible for young girls, from a critical feminist perspective, this narrative is problematic because it positions sport as a male endeavor, thus revealing the hurdles females must overcome to be respected as competitors. Although largely unintentional, such plots have the ability to reinforce a sense of false female empowerment or "girl power" that is undermined by the lead character's need to prove herself to society, male coaches, and teammates once she is in the sport or on the team. Cooky (2010) suggested that increasing the celebration of female athletes in this way does not necessarily result in increased participation, opportunities, and cultural shifts in the sporting world for females. The problem of opportunity is emphasized and also possible to be overcome solely by an individual. Issues with addressing opportunity as the problem with female sport falls short of the root issue-the entrenched gender inequality that has resulted in the perpetuation of gender stereotypes through the generations (Cooky, 2010).

The lone girl. A similar message was provided through a "lone girl" rhetoric on Catching the Moon by Crystal Hubbard. The term "lone girl" has been used in the sport literature to describe girls who participate on predominantly male teams (Kane, 1998). The storylines appear to celebrate "girl power" as females demonstrate the capability necessary for entry onto a male team. Importantly, this process inadvertently sends negative messaging to young girls in several ways. First, the "lone girls" are typically depicted negatively as "tomboys," emphasizing their more masculine qualities. Second, the message conveyed is typically one that requires the "lone girl" to prove she has the capability to compete on the boys' team-thus, suggesting the novelty and general improbability of such a scenario. In Hubbard's story, Marcenia dreams of competing professionally. She tries to join a baseball camp but is denied despite her skill because she is a girl. After persistently trying to join the camp, demonstrating her skill by playing with the boys, she is finally noticed and accepted when she "takes the biggest chance in baseball" (p. 13) and steals home. Although the story shows how Marcenia was challenging the stereotype that baseball is a sport predominantly played by boys, she also felt the need to prove her worth to the male coach of the baseball camp. She is depicted as being uninterested in things like dolls and in a profession like teaching or nursing, and is discouraged by her father to play baseball, told to stop "acting like a tomboy" (p. 19). This is illustrative of the distinction between feminism and athleticism that is commonly made in the media about female athletes (Heinecken, 2015).
Olsson and Martiny (2018) found that children's beliefs and behaviors about gendered occupations could be changed by showing them relatable individuals in counter-stereotypical or genderincongruent occupations over a period of time. Thus, sport fiction authors could instead challenge the stereotype by illustrating a female or mix-sex team of a traditionally male sport in the first place. If authors can promote a shift toward normalizing girls in sports that are not individual or those that are commonly occupied by females, it may help reduce stereotyping toward female athletes and the sports they participate in, and subsequently promote young girls' engagement in a variety of sports.

\section{Nine- to 12-Year-Olds: Sport as a Context for Shutdowns and Show-Offs}

Contrary to the previous age groups, the reinforcement of gender stereotypes was more explicit in this final age group of books. For example, the illustrations depict "Barbie-like" female characters with big eyes and lips, tall and thin bodies, wearing make-up and feminine clothing when not participating in the sport. During the sport participation, whether it be gymnastics or soccer, the female characters look "put together" with neat hair and makeup. Moreover, this group of books all followed a similar narrative where the central storyline revolved around interpersonal conflict portrayed as typical of adolescent females. As such, the main themes coming out of this age group were: rivalry and drama and the mean girl.

Rivalry and drama. This grouping of books reinforced traditional gender stereotypes about female athletes by largely portraying them as having difficulty working well with teammates and regulating their emotions. The typical plot involved one of the main characters feeling threatened by another, and conflict would ensue that would negatively affect the sport context. For example, in Soccer Surprise by Jake Maddox, a new girl to the team, Alex, made a simple mistake on the field that cost her team the game. Her teammates were upset and made comments to hurt Alex's feelings and purposefully ignored and excluded her. The conflict was eventually resolved when Alex apologized to her teammates; however, her initial refusal to apologize and the treatment she received from her teammates echoed the "drama" and emotional portrayal associated with female sport. This theme was also apparent in the names of chapters and the book titles themselves. For example, book titles included: Running Rivals, Soccer Sabotage, and Soccer Show Off. The pattern continues throughout the chapter titles which included: "Intimidation," "The Showdown," "Showing Off," "Odd Girl Out," "You Don't Deserve It," and "The Silent Treatment."

This idea is representative of common stereotypes of female sports and thus, within this age category, the reinforcement of gender stereotypes was clear. Moreover, it fails to show sport as a context for female bonding and comradery (Heinecken, 2015). Throughout this grouping of books, the sport itself was largely deemphasized and simply represented a medium or context to illustrate the dynamics of female relationships. Rather than highlighting the physical and social benefits of sport for girls and encouraging their participation, interpersonal conflicts were emphasized and made the focus of the storylines. Thus, the dynamics of female relationships were presented in a negative light. To this end, the messaging failed to teach young girls the benefits of supporting one another and celebrating each other's talents and victories. Instead, it pinned them against one another and created the illusion that girls are more focused on conflict or winning the attention of a male, at the expense of betraying friends and teammates. It is, however, important to recognize that the social aspect of sport is a significant 
driving force for participation. As such, it is not that female relationships should be downplayed, but that more positive representations are needed. Indeed, careful attention needs to be paid to not simultaneously reinforce stereotypes that paint females as participating solely for reasons that play into their nurturing nature and desire to make friends rather than compete.

The mean girl. Each book in this category also had one or more "mean girl" characters. This character would instigate issues with other females by treating their athletic abilities as significantly lesser than their own, by being overly competitive with teammates, or by causing trouble and/or sabotaging their competitors. Similarly, competitors were generally depicted as "enemies" in these books, even when the competitor was a part of the same team. For instance, in Dancing Solo by Jake Maddox, ballet dancer Sarah is confident that she is the best in her class and lets everyone else in the class know it. Because of this, the majority of the girls did not like Sarah, which was amplified when she began to treat certain classmates poorly when they threatened her position as the lead in their upcoming recital.

Based on the findings from this age group, in particular, it appears that many of the traditional perspectives about female sport persist. It appears that it is not enough to only increase the visibility of female athletes with the hopes of improving long-term participation. As Meier (2015) stated, more often than not, female athlete role models are portrayed in a stereotypical manner where emphasis is placed on femininity and sexuality rather than their athleticism. This is seen overtly in the illustrations from this set of books, in which girls are seen in a "Barbie-like" manner. Simply increasing the number of female athlete role models does not guarantee young girls will receive encouragement and support (Meier, 2015). In fact, when female sport role models are depicted reinforcing traditional stereotypes (similar to those in this grouping of books) their function becomes counterproductive and negative implications can ensue for those who deviate from the expectations of their role models (Meier, 2015). Ultimately, it further reduces the number of visible role models for girls and fails to contribute to a reconceptualization of the female athlete.

It is important to note that support should be demonstrated by role models that are not solely female. In fact, support from male role models has been recognized as just as important for the continued participation of girls in sport (Canadian Women and Sport, 2016). As such, authors should consider including more supporting male characters to further illustrate this type of support. To this end, role models do not need to be famous or successful for individuals to draw influence, in fact, one's own peers can serve as role models (Bandura, 1986). Thus, authors should also focus on creating characters that readers can identify with and relate to as this is an essential component encouraging girls to participate in sport and adopt positive gender schemas.

\section{Conclusion}

The purpose of this study was to explore the extent to which children's sport-based books promoted the engagement of girls in sport. Specifically, we identified three main themes, including "Feminine" sports as a context for diversity and learning, emphasizing the process and the company, and sport as a context for shutdowns and show-offs. On the surface, the sample of books appeared to promote the engagement of girls in sport. However, an examination using narrative inquiry and applying a critical feminist lens revealed resistance and a false impression of female empowerment that, at times, reinforced patriarchy at an implicit level. This led to the addition of subthemes such as "feminine sports are appropriate sports," "proving she belongs," "the lone girl," "rivalry and drama," and the "mean girl." The identification of such narratives is problematic considering the role that culture plays in children's development of gender schemas and given the known physical and psychosocial benefits associated with sport participation that girls may be missing out on as a result.

Our findings suggest the need for greater attention toward the complexity of female sport and a cultural shift in thinking about gender equity rather than simply increasing access for female athletes. Adults should be more aware of the implicit messages of stereotyping in such books as they represent a primary way in which children are socialized. Authors should continue to use positive role modeling to encourage young girls to embrace their differences and to recognize how they can utilize their unique talents to contribute to the team. At the same time, however, they must also be mindful of not framing sports as a male endeavor through "lone girl" and "proving she belongs" narratives and, instead, stress the importance of sampling a variety of sports and depicting supporting male role models in adaptive ways.

In addition, this study makes innovative methodological contributions to the research in this area. To our knowledge, this is the first analysis of children's sport-based books to use a pragmatic search strategy. Such a strategy allowed us to obtain a realistic list of books captured in a practical way by individuals outside of the research team. With respect to our methods, an additional unique feature was the grouping of books according to the intended age of the target audience during analysis. This approach enabled us to explore trends both within a particular age group as well as across the age spectrum to determine how the messaging changed with age.

However, the findings should be considered in light of certain limitations. First, only a sample of books from larger series was included, and so, generalizations about those series were made. Future researchers could engage with an entire series of girls sport-based fiction books to draw conclusions about the collection as we may have missed exceptions. Second, the third and oldest age grouping contained six out of seven books that were part of the same series. As such, generalizations about this specific age grouping were made based on the messaging of one author. Given the findings of this group, in particular, further research is needed to explore the narratives targeted toward this audience in other books and series.

It appears that it is not enough to emphasize the visibility of female athletes with the hopes of improving long-term participation. Instead, a critical look into the current state of socialization processes and the messaging that girls are exposed to reveals a larger issue that suggests the need for a reconceptualization of female sport and the female athlete in broader society. Given that children's ideas of culture and gender are informed by the books they are exposed to, the first step toward this reconceptualization could be for authors to incorporate some of the suggestions outlined throughout this paper to alternatively showcase and promote sport as a context for both males and females.

\section{References}

Adams, C., \& Leavitt, S. (2018). "It's just girls' hockey": Troubling progress narratives in girls' and women's sport. International Review for the Sociology of Sport, 53(2), 152-172. doi:10.1177/10126902 16649207

Allen, J.B. (2003). Social motivation in youth sport. Journal of Sport and Exercise Psychology, 25(4), 551-567. doi:10.1123/jsep.25.4.551 
Bandura, A. (1997). Self-efficacy: The exercise of control. New York, NY: W.H. Freeman and Company.

Bandura, A., and National Institute of Mental Health. (1986). Prentice-Hall series in social learning theory. Social foundations of thought and action: A social cognitive theory. Englewood Cliffs, NJ: Prentice-Hall.

Baumeister, R.F., \& Leary, M.R. (1995). The need to belong: Desire for interpersonal attachments as a fundamental human motivation. Psychological Bulletin, 117(3), 497-529. PubMed ID: 7777651 doi:10. 1037/0033-2909.117.3.497

Beauchamp, M.R., Bray, S.R., Eys, M.A., \& Carron, A.V. (2002). Role ambiguity, role efficacy, and role performance: Multidimensional and mediational relationships within interdependent sport teams. Group Dynamics: Theory, Research, and Practice, 6(3), 229-242. doi:10. 1037/1089-2699.6.3.229

Boiché, J., Plaza, M., Chalabaev, A., Guillet-Descas, E., \& Sarrazin, P. (2014). Social antecedents and consequences of gender-sport stereotypes during adolescence. Psychology of Women Quarterly, 38(2), 259-274. doi:10.1177/0361684313505844

Braun, V., Clarke, V., \& Weate, P. (2016). Using thematic analysis in sport and exercise research. In B. Smith \& A.C. Sparkes (Eds.), Routledge handbook of qualitative research in sport and exercise (pp. 191-205). London, UK: Routledge.

Bussey, K., \& Bandura, A. (1999). Social cognitive theory of gender development and differentiation. Psychological Review, 106(4), 676713. PubMed ID: 10560326 doi:10.1037/0033-295X.106.4.676

Canadian Women and Sport. (2012). Actively engaging women and girls: Addressing the psycho-social factors. Retrieved from https:// womenandsport.ca/wp-content/uploads/2020/03/Actively-EngagingWomen-and-Girls_Canadian-Women-Sport.pdf

Canadian Women and Sport. (2016). Women in sport: Fueling a lifetime of participation. Retrieved from https://womenandsport.ca/wp-content/ uploads/2020/03/Fuelling-a-Lifetime-of-Participation-Report_CanadianWomen-Sport.pdf

Clearinghouse of Sport. (2020, July). Women in sport. Retrieved from $\sim \mathrm{https}: / /$ www.clearinghouseforsport.gov.au/knowledge_base/organised_sport/ sport_and_government_policy_objectives/womens_sport\#: :text= Participation,participate\%20in\%20sport\%20related\%20activities

Cooky, C. (2010). Understanding popular culture images of "girl power!" and sport. In S.S. Spickard \& B. Lampman (Eds.), Learning culture through sports: Perspectives on society and organized sports (2nd ed., pp. 210-226). Lanham, MD: Rowman \& Littlefield.

Côté, J., Baker, J., \& Abernethy, B. (2007). Practice and play in the development of sport expertise. In R. Eklund \& G. Tenenbaum (Eds.), Handbook of sport psychology (3rd ed., pp. 184-202). Hoboken, NJ: Wiley.

Côté, J., Lidor, R., \& Hackfort, D. (2009). ISSP position stand: To sample or to specialize? Seven postulates about youth sport activities that lead to continued participation and elite performance. International Journal of Sport and Exercise Psychology, 7(1), 7-17. doi:10.1080/ 1612197X.2009.9671889

Crane, J., \& Temple, V. (2015). A systematic review of dropout from organized sport among children and youth. European Physical Education Review, 21(1), 114-131. doi:10.1177/1356336X14555294

Dinella, L.M., \& Weisgram, E.S. (2018). Gender-typing of children's toys: Causes, consequences, and correlates. Sex Roles, 79(5-6), 253-259. doi:10.1007/s11199-018-0943-3

Eime, R.M., Young, J.A., Harvey, J.T., Charity, M.J., \& Payne, W.R. (2013). A systematic review of the psychological and social benefits of participation in sport for children and adolescents: Informing development of a conceptual model of health through sport. International Journal of Behavioral Nutrition and Physical Activity, 10, 1-21. doi:10.1186/1479-5868-10-98
Erickson, K., Wright, E., Kochanek, J., \& Vierimaa, M. (2020). Peer influence and youth development. In M.W. Bruner, M.A. Eys, \& L.J. Martin (Eds.), The power of groups in youth sport (pp. 221-240). London, UK: Academic Press. doi:10.1016/b978-0-12-816336-8.00013-5

Eys, M.A., Godfrey, M., \& Kim, J. (2020). Role involvement in youth sport teams. In M.W. Bruner, M.A. Eys, \& L.J. Martin (Eds.), The power of groups in youth sport (pp. 33-48). London, UK: Academic Press. doi:10.1016/b978-0-12-816336-8.00003-2

Glenn, W.J., \& King-Watkins, D. (2019). Being an athlete or being a girl: Selective identities among fictional female athletes who play with the boys. Children's Literature Association Quarterly, 44(3), 290-309. doi:10.1353/chq.2019.0034

Glenn, W.J., \& King-Watkins, D. (2020). Fictional girls who play with the boys: Barriers to access in the transition to male-dominated sports teams. Children's Literature in Education, 51(3), 309-331. doi:10. 1007/s10583-019-09384-7

Hamilton, M.C., Anderson, D., Broaddus, M., \& Young, K. (2006). Gender stereotyping and under-representation of female characters in 200 popular children's picture books: A twenty-first century update. Sex Roles, 55(11-12), 757-765. doi:10.1007/s11199-006-9128-6

Hanson, V. (2012). The inequality of sport: Women<men. The Review: A Journal of Undergraduate Student Research, 13(1), 15-22.

Heinecken, D. (2015). Pretty tough sports and the promotion of female empowerment in young adult sports fiction. The Lion and the Unicorn, 39(1), 23-41. doi:10.1353/uni.2015.0006

Heinecken, D. (2016). Empowering girls through sport? Sports advice books for young female readers. Children's Literature in Education, 47(4), 325-342. doi:10.1007/s10583-016-9281-7

Howells, K., \& Fletcher, D. (2015). Sink or swim: Adversity-and growthrelated experiences in Olympic swimming champions. Psychology of Sport and Exercise, 16, 37-48. doi:10.1016/j.psychsport.2014. 08.004

Janssen, I., \& LeBlanc, A.G. (2010). Systematic review of the health benefits of physical activity and fitness in school-aged children and youth. The International Journal of Behavioral Nutrition and Physical Activity, 7(1), 40. doi:10.1186/1479-5868-7-40

Kane, M.J. (1998). Fictional denials of female empowerment: A feminist analysis of young adult sports fiction. Sociology of Sport Journal, 15(3), 231-262. doi:10.1123/ssj.15.3.231

Lazar, M. (Ed.). (2005). Feminist critical discourse analysis: Gender, power and ideology in discourse. New York, NY: Springer. doi:10. 1057/9780230599901

Leaper, C., \& Friedman, C.K. (2007). The socialization of gender. In J.E. Grusec \& P.D. Hastings (Eds.), Handbook of socialization: Theory and research (pp. 561-587). New York, NY: Guilford Press.

Martin, J. (2003). Feminist theory and critical theory: Unexplored synergies. In M. Alvesson \& H. Willmott (Eds.), Studying management critically (pp. 66-91). London, UK: Sage. doi:10.4135/9781446 220030.n4

Meier, M. (2015). The value of female sporting role models. Sport in Society, 18(8), 968-982. doi:10.1080/17430437.2014.997581

Moritz, S.E., Feltz, D.L., Fahrbach, K.R., \& Mack, D.E. (2000). The relation of self-efficacy measures to sport performance: A metaanalytic review. Research Quarterly for Exercise and Sport, 71(3), 280-294. PubMed ID: 10999265 doi:10.1080/02701367.2000. 10608908

Nodelman, P. (2008). The hidden adult: Defining children's literature. Baltimore, MD: John Hopkins University Press.

Olsson, M., \& Martiny, S.E. (2018). Does exposure to counterstereotypical role models influence girls' and women's gender stereotypes and career choices? A review of social psychological research. Frontiers in Psychology, 9(2264), 1-15. doi:10.3389/fpsyg.2018.02264 
Phoenix, C., \& Rich, E. (2016). Visual research methods. In B. Smith \& A.C. Sparks (Eds.), Routledge handbook of qualitative research in sport and exercise (pp. 161-173). London, UK: Routledge.

Plaza, M., Boiché, J., Brunel, L., \& Ruchaud, F. (2017). Sport = male ... But not all sports: Investigating the gender stereotypes of sport activities at the explicit and implicit levels. Sex Roles, 76(3-4), 202-217. doi:10.1007/s11199-016-0650-x

Poitras, V.J., Gray, C.E., Borghese, M.M., Carson, V., Chaput, J.P., Janssen, I., ... Sampson, M. (2016). Systematic review of the relationships between objectively measured physical activity and health indicators in school-aged children and youth. Applied Physiology, Nutrition, and Metabolism, 41(6), S197-S239. doi:10.1139/ apnm-2015-0663

Renaissance Learning Inc. (2016). What kids are reading and how they grow. Retrieved from http://blogs.edweek.org/edweek/high_ school_and_beyond/What\%20Kids\%20Are\%20Reading\%202017_ Final.pdf

Riessman, C.K. (1993). Narrative analysis (Vol. 30). Thousand Oaks, CA: Sage.

Riessman, C.K. (2008). Narrative methods for the human sciences. Thousand Oaks, CA: Sage.

Roper, E.A., \& Clifton, A.M. (2013). The representation of physically active girls in children's picture books. Research Quarterly for Exercise and Sport, 84(2), 147-156. PubMed ID: 23930540 doi:10.1080/02701367.2013.784844

Sheridan, D., Coffee, P., \& Lavallee, D. (2014). A systematic review of social support in youth sport. International Review of Sport and Exercise Psychology, 7(1), 198-228. doi:10.1080/1750984X.2014.931999

Singleton, E. (2006). The girls of central high: How a progressive era book series for girls furthered the cause of female interschool sport. Children's Literature in Education, 37(3), 211-227. doi:10.1007/ s10583-006-9008-2

Smith, A.L. (2003). Peer relationships in physical activity contexts: A road less traveled in youth sport and exercise psychology research. Psychology of Sport and Exercise, 4(1), 25-39. doi:10.1016/S14690292(02)00015-8

Smith, A.L., \& McDonough, M.H. (2008). Peers. In A.L. Smith \& S.J.H Biddle (Eds.), Youth physical activity and sedentary behaviour challenges and solutions. Champaign, IL: Human Kinetics. doi:10. 5040/9781492595601.ch-012
Smith, B. (2016). Narrative analysis in sport and exercise: How can it be done? In B. Smith \& A.C. Sparkes (Eds.), Routledge handbook of qualitative research in sport and exercise. London, UK: Routledge. doi:10.4324/9781315762012

Smith, B., \& Sparkes, A.C. (2009). Narrative inquiry in sport and exercise psychology: What can it mean, and why might we do it? Psychology of Sport and Exercise, 10(1), 1-11. doi:10.1016/j.psychsport.2008. 01.004

Sport England. (2019). Active lives children and young people survey: Attitudes towards sport and physical activity. Retrieved from https:// sportengland-production-files.s3.eu-west-2.amazonaws.com/s3fspublic/active-lives-children-survey-2017-18-attitudes-report.pdf

Strachan, L., Côté, J., \& Deakin, J. (2009). An evaluation of personal and contextual factors in competitive youth sport. Journal of Applied Sport Psychology, 21(3), 340-355. doi:10.1080/10413200903 018667

Tsang, S.K., Hui, E.K., \& Law, B. (2012). Self-efficacy as a positive youth development construct: A conceptual review. The Scientific World Journal, 12(4), 1-7. doi:10.1100/2012/452327

Weiller, K.H., \& Higgs, C.T. (1989). Female learned helplessness in sport: An analysis of children's literature. Journal of Physical Education, Recreation \& Dance, 60(6), 65-67. doi:10.1080/07303084.1989. 10604486

Weisgram, E.S., Fulcher, M., \& Dinella, L.M. (2014). Pink gives girls permission: Exploring the roles of explicit gender labels and gendertyped colors on preschool children's toy preferences. Journal of Applied Developmental Psychology, 35(5), 401-409. doi:10.1016/ j.appdev.2014.06.004

White, R.L., \& Bennie, A. (2015). Resilience in youth sport: A qualitative investigation of gymnastics coach and athlete perceptions. International Journal of Sports Science \& Coaching, 10(2-3), 379-393. doi:10.1260/1747-9541.10.2-3.379

Whiteside, E., Hardin, M., DeCarvalho, L.J., Carillo, N.M., \& Smith, A.N. (2013). "I am not a cow": Challenging narratives of empowerment in teen girls sports fiction. Sociology of Sport Journal, 30(4), 415-434. doi:10.1123/ssj.30.4.415

Women's Sport Foundation. (2020). Keeping girls in the game: Factors that influence sport participation. Retrieved from https://www. womenssportsfoundation.org/wp-content/uploads/2020/02/KeepingGirls-in-the-Game-FINAL-web.pdf 